\title{
Epigenetic Modifications in Plant Development and Reproduction
}

\author{
Vladimir Brukhin ${ }^{1,2, *}$ Emidio Albertini ${ }^{3}$
}

\author{
${ }^{1}$ Plant Genomics Laboratory, ChemBio Cluster, ITMO University, 9 Lomonosova Street, Saint- \\ Petersburg, 191002, Russia \\ ${ }^{2}$ Department of Plant Embryology \& Reproductive Biology, Komarov Botanical Institute RAS, 2 \\ Professor Popov Street, St. Petersburg, 197376 Russia \\ ${ }^{3}$ University of Perugia, Dept. of Agricultural, Food and Environmental Sciences, Borgo XX Giugno \\ 74, 06121 Perugia, Italy, e-mail: emidio.albertini@unipg.it \\ *Corresponding Email: vbrukhin@gmail.com
}

\begin{abstract}
Plants are exposed to highly fluctuating effects of light, temperature, weather conditions and many other environmental factors throughout their life. As sessile organisms, unlike animals, they are unable to escape, hide or even change their position. Therefore, the growth and development of plants is largely determined by interaction with the external environment, the success of this interaction depends on the ability of the phenotype plasticity, which is largely determined by epigenetic regulation. In addition to how environmental factors can change the patterns of genes expression, epigenetic regulation determines how genetic expression changes during the differentiation of one cell type into another, and how patterns of gene expression are passed from one cell to its descendants. Thus, one genome can generate many 'epigenomes'. Epigenetic modifications acquire special significance during the formation of gametes and plant reproduction, when epigenetic marks are eliminated during meiosis and early embryogenesis and later reappear. However, during asexual plant reproduction, when meiosis is absent or suspended, epigenetic modifications that have arisen in the parental sporophyte can be transmitted to the next clonal generation practically unchanged. In plants that reproduce sexually and asexually, epigenetic variability has different adaptive significance. In asexuals, epigenetic regulation is of particular importance for imparting plasticity to the phenotype, when the genotype remains unchanged for many generations of individuals. Of particular interest is the question of the possibility of transferring acquired epigenetic memory to future generations and its potential role for natural selection and evolution. All these issues will be discussed to some extent in this review. In the last two decades, a lot of data on the epigenetic regulation of plants has appeared, as well as works summarizing the accumulated knowledge (1-4), nevertheless, many questions remain unclear, and a number of results are contradictory. New in this area data is constantly
\end{abstract}


emerging. We tried to take into account and discuss the main findings and conclusions in this field.

Keywords: Epigenetics, plant development, microsporogenesis, megasporogenesis, male and female gametophytes, embryogenesis, endospermogenesis, sexual and asexual reproduction 


\section{1) Epigenetic systems in plants}

Epigenetic regulation of gene expression is understood primarily as DNA methylation, modification of histones by methylation, acetylation, and ubiquitination of histone N-tails, and post-transcriptional silencing through small non-coding RNAs. In the model plant Arabidopsis, more than 130 genes are known that are regulated epigenetically (2).

In plants, 5-cytosine is the main site of DNA methylation. The latter occurs in the three contexts, symmetric $\mathrm{CH}, \mathrm{CHG}$, and asymmetric $\mathrm{CHH}$, where $\mathrm{H}$ is any nucleotide except $\mathrm{G}$. In the symmetrical context, the most frequently methylated are repetitive motives of $\mathrm{CG}$ or $\mathrm{CHG}$, referred to as CG islands. CG methylation during replication cycles is supported by the enzyme methyltransferase 1 (MET1) in a semi-conserved way. Methylation in the context of CHG is supported by chromomethylase3 (CMT3) methyltransferase. Due to its asymmetric nature, $\mathrm{CHH}$ must be methylated de novo after each round of replication. $\mathrm{CHH}$ methylation sites are catalyzed by Domain Rearranged Methyltransferase2 (DRM2), which is involved in plant-specific RNAdirected DNA methylation (RdDM). $\mathrm{CHH}$ methylation can also be performed by chromomethylase2 (CMT2) homologous to CMT3 independently of RdDM. The enzyme Decrease in DNA Methylation 1 (DDM1) remodels chromatin by removing the histone $\mathrm{H} 1$ linker in the compact heterochromatic regions, providing access of methyltransferases to DNA. DRM2 mediated methylation is mainly involved in the methylation of euchromatic regions, including short transposable elements (TE) and edge fragments of the long TE, as well as pericentromeric sites (5).

An important role in the biogenesis of small interfering RNAs is played by polymerase IV and polymerase V, which are plant homologues of polymerase II, and which specialize in the production of small RNAs required for RdDM. Polymerase IV synthesizes single-stranded RNA (ssRNA) on silencing targets, retrotransposons, viruses, transgenes, or repetitive genes. RNA-dependent RNA polymerase2 (RDR2) promotes the formation of double-stranded RNA (dsRNA) from ssRNA. Next, Diserlike3 (DCL3) cuts dsRNA into 24 and 23-nt small interfering RNAs (siRNAs), one strand of the duplex are loaded to Argonaute (AGO4). AGO4 bound siRNAs complement with polymerase $\mathrm{V}$ transcripts and recruit DRM2, which catalyzes de novo methylation of the genome homologous sites in all contexts $(6,7)$.

Active DNA demethylation occurs via DNA glycosylase Repressor of Silencing1 (ROS1), Demeter (DME), Demeter-like2 (DML2), and DML3. The mode of action of glycosylases is through the elimination of methylated cytosine, replacing it with nonmethylated cytosine. During plant reproduction and further ontogenesis, various modes of dynamic DNA methylation and demethylation in all contexts provides the necessary genetic regulation of development (8).

In addition to DNA methylation, the modification of histones, nuclear proteins involved in the packaging of DNA strands in the nucleus and in the epigenetic regulation of transcription and replication, is of great importance for genetic regulation. Chromatin remodeling (a change in its structure) occurs, among other 
things, due to histone modifications. It alters the availability of DNA for transcription factors and polymerases, thereby regulating gene expression and contributing to phenotype variability. Like DNA methylation, chromatin remodeling plays an important role in plant reproduction and ontogenesis. Basically, the epigenetic marks are the methylation of lysines in histone H3. Thus, the trimethylation of lysine 3 and lysine 4 in histone $\mathrm{H} 3$ (H3K4me3 and H3K3me3, respectively) leads to the formation of "active" chromatin, which allows genes to be expressed, while dimethylation of lysine 9 and trimethylation of lysine 27 (H3K9me2 and H3K27me3, respectively) produces repressive chromatin, which suppresses the transcriptional activity of genes. The formation of repressive chromatin containing H3K27me3 regulates evolutionarily conserved complex of proteins Polycomb Repressive Complex 2 (PRC2), which regulates many developmental processes of reproduction and the initial stages of seed formation in plants.

Histone acetylation is usually an epigenetic mark associated with active chromatin and transcriptional activity (9).

\section{2) Methylation in the meristem development}

A distinctive feature of plant morphogenesis is the totipotency of some cells of plant meristems, which perform the function of stem cells. These cells can transform into any cell of a plant tissue or organ. Since meristems persist throughout the whole life of a plant, new organs and tissues can form indefinitely, and in this sense, plants are immortal. In other words, clones of plant genotypes can exist indefinitely through vegetative propagation, as well as by in vitro propagation in tissue culture. In plants, in addition to the shoot apical meristem, which gives rise to leaves, stem and flower buds, there are also lateral, intercalary, and marginal meristems, whose cells, under certain conditions, are capable of organogenesis and somatic embryogenesis. In Waddington's terms, meristematic totipotent plant cells are polyvalent and can follow many trajectories of the epigenetic landscape $(10,11)$.

During the transition from the vegetative to the generative phase of development in the shoot apical meristem (SAM), the patterns of DNA and histone methylation change significantly (12). After epigenetic modifications occur in the stem cells of the meristems due to gradients of phytohormones and interaction with the environment, the shoot apical meristem turns into a flower meristem, in which ovary formation and meiosis take place. Unlike animals, plants do not form germ lines directly; instead, they form haploid male and female gametophytes in which gametogenesis occurs. Since male and female gametophytes are haploid, possible harmful mutations that have arisen are not compensated by the homologous allele, and gametophytes carrying such mutations are aborted (13). Due to the peculiar gametogenesis, many epigenetic marks in plants are not completely erased, as in animals, but are temporarily suppressed by small non-coding RNAs of neighboring tissues.

Perhaps the first epiallele in nature was found in toadflax (Linaria vulgaris) when studying the shape of the flower, carried out back by Karl Linnaeus. In wild-type 
plants, the flower shape is zygomorphic, that is, bilaterally symmetric, while several peloric flowers develop radial symmetry, i.e., become actinomorphic (Fig. 1). Genetic analysis showed that radial symmetry arises because of methylation of the Lcyc locus, while transcripts of this gene are not found in actinomorphic flowers (14). Lcyc is homologous to the Cycloidea gene, which controls the symmetry in the snapdragon flower (15).

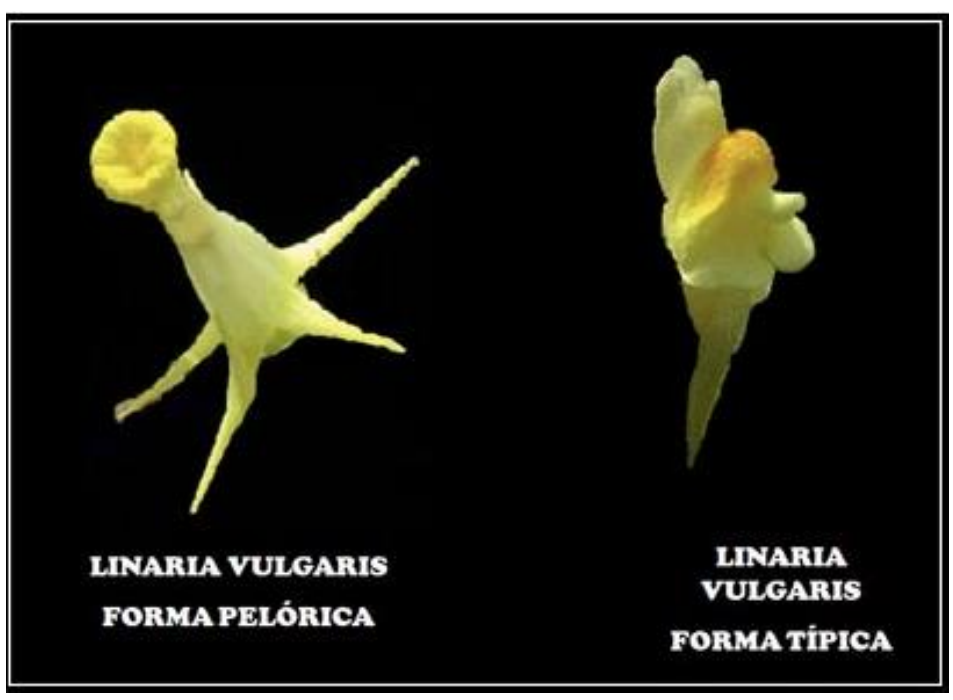

Figure 1. Actinomorphic (peloric) and zygomorphic (most typical) flowers in toadflax (Linaria vulgaris). The symmetry and shape of the flower is determined by the methylation of the Lcyc gene.

Another well-known example of epiallele is the CNR (Colorless non-ripening) locus in tomatoes (16). In the mutants with this epiallele, seed maturation is suppressed, and colorless mealy fruits are formed. Genetic analysis showed that in individuals containing the mutant allele, the SBP transcription factor is poorly expressed due to the high methylation of the upstream region of the Le SPL-CNR gene.

Epimutations occur much more often and faster than proper mutations. However, unlike the latter, epimutations are reversible and thus are of great importance in the quick tuning and plasticity of the phenotype. Epigenetic diversity can provide phenotypic variability, which is valuable both for the fitness of the plant populations to changing environments and could be used for breeding of agricultural plants.

3) Epigenetic regulation of microsporogenesis and male gametophyte development.

As already mentioned, in plants, primary germ cells do not directly enter spermatogenesis and oogenesis, in contrast to animals. Instead, in the flower meristem pollen mother cells (PMCs) in anthers and megaspore mother cells (MMCs) in ovaries are formed as a result of two meiotic divisions followed by the series of mitotic 
divisions producing haploid male and female gametophytes, where male and female gametes origin, respectively $(15,16)$. In angiosperms male and female gametophytes, despite their small size and small number of cells, are excellent models for studying morphogenesis and epigenetic control of cell growth and specialization, cell polarity and signaling processes.

In case of pollen development, which occurs in the anthers, two stages can be distinguished, microsporogenesis and microgametogenesis. Diploid microsporocytes, or PMCs, are formed in the sporogenous layer of the anther. Two meiotic divisions of PMC produce tetrad of four haploid cells. Then tetrads separate to individual microspores. Afterwards two mitotic divisions take place - in the first asymmetric cytokinesis forms a large vegetative and a smaller generative cell, followed by the generative cell division producing two sperm cells, while the vegetative cell doesn't divide any more. So, mature pollen grain consists of the three cells, a larger vegetative cell, which controls and implements the growth of the pollen tube during fertilization, and two smaller sperm cells, which take part in double fertilization.

Epigenetic rearrangements play an important role in the regulation of both male and female gametophytes development, as well as in fertilization.

In Arabidopsis it has been shown that in the PMC methylation level in a symmetric context, CG and CHG, was higher compared to asymmetric context, $\mathrm{CHH}$ (19). It is known that symmetric methylation occurs mainly in transposable elements, while asymmetric hypermethylation usually takes place in protein-coding genes. It is likely that increased methylation in a symmetric context promotes suppression of TE activity, which ensures genome stability before and during meiosis. At the same time, inactivation of methylation in an asymmetric context promotes the activation of genes necessary for launching sperm cell formation programs and further fertilization. In addition to DNA methylation, during the maturation of PMCs, a dramatic reorganization of chromatin occurs, which promotes the commence of meiosis. The change from the mitotic to the meiotic phase is accompanied by an increase of permissive chromatin (H3K4me3) and a reduction of repressive chromatin (H3K27me1 and H3K27me3) (20). After meiosis and asymmetric mitotic division of the haploid microspore, the vegetative cell becomes roundish, it has an increased level of methylation in the $\mathrm{CHH}$ regions, while it significantly loses the Centromere Specific Histone H3 (CENH3), because of the decondensation of pericentromeric heterochromatin, local hypomethylation due to the activity of DME/ROS1 demethylases, and activation of transposable elements is also observed (21-23). Hypomethylation of TEs results in the generation of 21-22 nt siRNAs, which are transported to the sperm cells to suppress their TEs by RdDM methylation (21). In general, whole-genome cell-specific methylation profiling revealed a high level of CG and CHG methylation in DNA of microspores, sperm, and vegetative cells during the entire period of pollen formation and development. While most of the $\mathrm{CHH}$ methylation is lost in the pericentromeric region of microspores and sperm cells, it is restored in the vegetative cells. 


\section{4) Epigenetic regulation of megasporogenesis and female gametophyte development.}

The formation of an angiosperm egg cell begins with the development of archesporial cells from the subepidermal layer of the flower bud's nucellus. Archesporial cells produce a diploid dense cytoplasmic, large nuclear the megaspore mother cell (MMC), or megasporocytes. MMC undergoes two meiotic divisions forming a tetrad of megaspores, one of which, referred as functional megaspore, passing through three rounds of mitosis, produces an eight-nuclear megagametophyte, also called as embryo sac. After cellularization the embryo sac becomes seven cellular: at one pole there is an egg apparatus, consisting of an egg cell and two synergids, the latter contribute to the attraction of the sperm cell and fertilization; and at the other pole there are three antipodal cells that take part in the nutrition of the embryo sac $(13,17)$. In the center of the embryo sac, there are two polar nuclei, which as a result from karyogamy fuse to form the homodiploid nucleus of the central cell. During fertilization, the pollen tube enters the embryo sac in the egg apparatus area, and one sperm fertilizes the egg cell, forming a diploid zygote, from which the embryo (new sporophyte) is then develops, and the second sperm fuses with the central cell nucleus, producing a triploid nucleus of the first endosperm cell (nourishing tissue for the embryo). This process is called double fertilization.

During megasporocyte formation (MMC), the level of DNA methylation temporarily decreases in the context of $\mathrm{CHH}$, but methylation in $\mathrm{CG}$ context remains basically unchanged (24). The specification and differentiation of the MMC, as well as the functional megaspore, is carried out, inter alia, through intercellular interactions by the mobile trans activating siRNAs (tasiRNAs) produced in the surrounding cells of nucellus and transported to the MMC, where they implement silencing at the transcriptional and translational level (25). It was shown in Arabidopsis that the formation of such siRNAs is regulated by AGO9, RDR6, and SDS3 (a suppressor of genetic silencing3) enzymes (26). Disruption of AGO5 expression in Arabidopsis nucellus impairs the initiation of megagametogenesis.

Methylation in the $\mathrm{CG}$ and $\mathrm{CHH}$ contexts remains stable throughout megagametogenesis. At the same time, as was found in Arabidopsis, CG methylation within genes and transposons of the central cell of the embryo sac was lower than that in sperm cells (27). Demethylation of DNA in the central cell was performed by the Demeter activity (28). This may indicate that the potential transcription of male genes is suppressed even before fertilization. During gametogesnesis in the embryo sac epigenetic regulation takes place by mobile non-coding tasiRNAs, so siRNAs from the central cell enter the egg cell and suppress the activity of transposable elements. The foregoing confirms the importance of epigenetic control in megasporgenesis and megagametogenesis. 
5) Role of epigenetics in fertilization, embryogenesis, and endospermogenesis. Imprinted genes.

Fertilization abolishes $\mathrm{CHH}$ hypomethylation of the paternal genome both in the embryo and in the endosperm (29). It is likely that remethylation of the paternal genome occurs via maternal siRNAs (30). One of the reasons for the epigenetic suppression of the male genome at the early stages of embryogenesis might be a maternal control of the size of the embryo and endosperm (31), as well as the recognition of self-pollen, which can be critical in interspecific crosses (32).

Proper and consistent methylation of the dividing egg cell genome is highly essential for the normal embryo development. Young embryos and endosperm tissues are hypomethylated in comparison with mature embryos, which reflects the high transcriptional activity of genes in the developing embryo and preparation for dormancy of the mature embryo $(33,34)$. However, during seed germination, the metabolic and, accordingly, transcriptional-genetic activity of the embryonic tissues increases again, which is accompanied by a decrease in the methylation level in the $\mathrm{CHH}$ context, which is associated with the activation of protein-coding genes expression (35).

Since the histones inherited from the egg and sperm are not reproduced in the cells of the embryo, but are synthesized anew, the epigenetic "memory" associated with the histone marks is eliminated and is not passed to the next generations of cells (36). Thus, embryogenesis is the second after meiosis checkpoint or clearing box, which removes genome epigenetic marks acquired by the maternal sporophyte. Compared to the embryo, the level of endosperm methylation is significantly lower, which reflects its high transcriptional and metabolic activity. At the same time, the paternal genomes (i.e., genomes introduced by sperm cells into the egg cell and the central cell of the embryo sac) of the embryo and endosperm are more methylated than maternal ones (28). Apparently, endosperm demethylation is also necessary to suppress the activity of transposable elements through the formation of siRNAs, which are transported into the cells of the adjacent embryo and, through RNA directed DNA methylation, methylate the terminal regions of the transposons, thereby inactivating them (37).

Important role in endosperm formation plays the histone lysine transferase proteins, which are members of the two groups Polycomb (PcG) and Trithorax (TrxG), are involved in the modification of histones due to methylation of lysines in histone tails. They maintain a transcriptionally suppressed and transcriptionally active state, respectively (38). Proteins containing Polycomb Repressive Complex2 (PRC2) are required at all stages of plant development and are under a strict genetic control, mainly through DNA demethylation. The main function of PRC2 in the central cell is to suppress its proliferation prior to fertilization. In Arabidopsis, PRC2 consists of the four main components (subunits) - MEA, FIS2, FIE, and MSI1. The genes encoding these subunits express in the central cell of the embryo sac, and mutations in any of these genes cause the development of endosperm independent of fertilization, i.e., 
autonomous development (31,39-41). In addition, mutations in the genes encoding the PRC2 subunits are imprinted, that is, they demonstrate a parental of origin effect, therefore, only alleles from one parent are expressed. For example, mutants mea and fis2 demonstrate a maternal effect, accompanied by abnormal seed development and excessive size of the embryo and endosperm, and embryo lethality is independent of the paternal contribution and gene dosage $(42,43)$. During normal development, only the maternal alleles of MEA and FIS2 are expressed, and their activation is mediated by DME demethylation $(43,44)$

Thus, in course of sexual embryogenesis, there is a secondary, after meiotic events, erasure of epigenetic marks occurs, so that methylation of DNA and histones is almost completely de novo. The level of methylation in the embryo is higher than in the endosperm and it continues to increase in both symmetric and asymmetric contexts as the embryo matures, which is necessary for stabilization of the genome by neutralizing mobile genetic elements, as well as for a gradual decrease in the activity of protein-coding genes to prepare the embryo for seed dormancy. Since the endosperm is metabolically active during the development of the seed, it partially or completely disappears in the mature seed, being absorbed by the tissues of the embryo, there is no need for increased methylation of its genome. An important role in the development of the embryo and endosperm is played by the proteins of the PRC2 complex, which methylates lysine K27 in histone $\mathrm{H} 3$ tail and thereby maintains the suppression of gene transcription. Also, the PRC2 complex promotes the asymmetric expression of some genes from the parental alleles (imprinting), which is necessary for the normal development of seed. Epigenetic regulation occurs somewhat differently during asexual reproduction of plants.

\section{6) Epigenetic inheritance by the next generations. Apomictic and asexual reproduction.}

Sustainable inheritance of epigenetic marks and their preservation in the future generations is an important condition for the acquisition of stable selective advantages by a plant population. As we discussed earlier, DNA demethylation occurs during meiosis and early embryogenesis, while de novo methylation takes place at the late stages of embryogenesis and continues throughout the entire subsequent ontogenesis of a new sporophyte. As for chromatin, the inheritance of its modifications is a rather complicated process. As one knows, during meiosis and after fertilization, histones are formed anew and, thus, epigenetic marks of histone tails are not transmitted from the previous generations. Nevertheless, there is a putative crosstalk between DNA methylation and chromatin remodeling. In this regard, given that the cytoplasm of the egg cell is inherited from MMC, some transmission of epigenetic information about the modification of histones by the RdDM mechanism is possible, bearing in mind that small non-coding RNAs are transferred from the MMC cytoplasm.

Despite the demethylation that occurs during meiosis and embryogenesis, some methylation patterns in the CG context are quite stable and can pass through meiosis 
and be inherited by the next generations $(45,46)$. However, methylation in the $\mathrm{CHH}$ and CHG contexts are more sensitive to meiotic resetting of methylation (47).

As shown in Arabidopsis, spontaneous nucleotide mutations are extremely rare, numbering 20 SNPs per genome after 30 plant generations originated from one plant, while new methylation was found in thousands of cytosines $(45,46)$. However, regular changes in methylation in large regions of genome in the same series of generations were also rarely found. That is, the homeostasis of methylation maintenance was quite stable due to the coordinated functioning of methylases, methyltransferases, and demethylases. There is an assumption that the emergence of new alleles is associated with differential methylation of transposons, which play a major role in the origin of new epialleles and their inheritance (47).

One of the striking examples of transgenerational inheritance of epigenetic modifications is the study of the acquisition of inherited methylation of some Arabidopsis genes caused by water stress (48). In this study, low relative humidity caused DNA methylation at two loci responsible for stomatal formation, accompanied by the synthesis of large amounts of small RNAs associated with this methylation. Acquired methylation appeared in several generations of offspring but was reversible if the stress leading to the methylation was not repeated.

In case of asexual reproduction, i.e., via vegetative parts of plants such as shoots, stolon, tubers, runners, rhizomes etc., and via somatic embryogenesis in tissue culture development of gametophytes is bypassed, therefore complete demethylation and deletion of histone marks does not occur. Thus, epigenetic patterns can be partially or completely transferred to the next generations of sporophytes. Accordingly, the epigenetic variability in reproductive and asexual plants is different. However, there is no suppression of transposon activity due to methylation by means of tasiRNA expression in the tissues surrounding the somatic embryo or the initial vegetative bud. This can lead to the mobilization of transposable elements and the emergence of new genotypes called somaclonal variants.

Apomixis is the reproduction via asexual seeds. It appears due to alternative expression of the genes responsible for sexual reproduction. Most of the apomictic plants are polyploids and highly heterozygous because they came to existence as a result of sophisticated hybridization. So, the epigenetic events, which affect polyploidization facilitate the transition from sexual to apomictic reproduction (17). Apomixis promotes a wider geographical distribution of the species within agamic complexes and isolates polyploids, helping the latter to preserve and reproduce in these complexes on a par with diploid sexuals. Apomictic reproduction is always facultative, which is due, among other things, to the reversibility of many epigenetic processes. The ability to return to sexual reproduction allows apomicts to participate in speciation and evolutionary processes. In apomicts, meiosis in nucells is either blocked during the first meiotic division, in the case of diplospory, or bypassed and replaced by apomeiosis resulting in apospory (49). In any case, in diploid apomicts a diploid embryo sac is formed, which morphologically is like the sexual embryo sac. In apomictic embryo sac diploid egg cell is genetically identical to the maternal sporophyte, it gives rise to a parthenogenetic embryo, which develops without 
fertilization (17). Endosperm, on the other hand, develops from a tetraploid central cell either autonomously, i.e., without fertilization, or pseudogamously, that is, after fertilization with haploid or diploid sperm cell, depending on whether meiosis occurs in the anthers or not. As a rule, meiosis in anthers takes place and pollen is usually haploid, the same as in sexual plants. Since during apomixis, as well as during vegetative reproduction, meiosis, which removes epigenetic modifications of the genome, is absent, the epigenetic mechanisms in apomicts act differently and epigenetic marks can be transmitted from generation to generation. Despite the lack of genetic variability, apomicts perfectly adapt to changing environments and can occupy huge habitats. In addition to clonal fixation of genome, which includes combinations of advantageous traits, success in the spread of apomicts is also ensured by epigenetic regulation, which largely determines the plasticity of their phenotypes and their high fitness to various environmental conditions. Since in the formation of clonal embryos there is no meiosis, which in the reproductive ovules performs the function of a clearing box, epigenetically formed apomictic genotypes can have transgenerational stability. Thus, epigenetic variants of apomicts perform the function of genetic variants of sexuals, providing fitness and the evolutionary potential of asexual offspring (1). Epigenetic pathways appear to be involved in restricting sexual female gametophyte formation to a single cell in both Arabidopsis and maize $(26,50$ 56). In particular, nucellar cells in ago9 mutants failed to undergo programmed cell death but instead initiated developmental processes reminiscent of apospory. While the apospory-like structures failed to develop further, this study provided evidence that epigenome-level regulations are important in directing female germ cell development. In maize, the loss-of-function ago104 (a homolog of AGO9) mutant produced apomixis-like phenotypes that gave rise to $70 \%$ functional unreduced female gametes (54).

Oxidative stress has been proposed as central to sex/apomixis switching in facultatively and cyclically apomictic eukaryotes $(58,59)$. Several lines of evidence suggest that transitions during reproduction and early seed development are epigenetically regulated by dynamic changes in chromatin state $(26,49,53-56)$. Moreover, several evidences indicate that DNA methylation pathway acts upon germline or germline associated cells. In fact, apomeiosis-like phenotypes were induced in reproductive cells by a deregulation of DNA methylation (50) and treatments of Boechera pistils resulted in a high frequency of conversions from Taraxacum type diplospory to normal meiotic tetrad formation (60).

Random (stochastic, non-directed) genetic modifications occur, such as genetic drift and modifications to adapt to the changing environment. Random epigenetic mutations can also participate in the formation of adaptive phenotypes through natural selection, provided they are transgenerational. Environment-directed epigenetic modifications arise in a targeted manner due to the interaction of the genotype with the environment; they provide the plasticity of the phenotype (61). Since the genotype in an asexual population is unchanged over a long series of generations, in case of some ancient apomicts sometimes thousands of years, their epigenetic regulation can turn on and off the expression of individual genes and gene families in response to environmental signals. This ensures the plasticity of 
phenotypes in asexual plants. Because in apomicts, the same genotype is transmitted to many generations, it must be resistant to a wide range of environmental changes, therefore, clonal genotypes have high mean fitness (62). Accidental methylation can occur either due to errors of the methylation enzymes or unusual environmental conditions. In some cases, stochastic methylation can cause persistent epimutation, which can be fixed by natural selection and passed on to subsequent generations, resembling a normal mutation in DNA sequences. However, as a rule, epimutations provide short-term adaptations to fluctuating environmental conditions. As shown above, the adaptive value of epigenetic variability in reproductive and apomictic plants is different.

During the last decade several studies have been carried out on apomictic species with the aim of identifying epigenetic changes related to the fate of the reproductive program (49). The apomixis locus resides in heterochromatic regions rich in transposons both in Paspalum simplex and in Pennisetum squamulatum $(63,64)$. In E. curvula sexual and apomictic genotypes produced differentially expressed TE-related sequences (65), and similar differences were noted for apomictic plants obtained by chromosome doubling (65). Podio et al. (2014) (66)reported a decrease of parthenogenesis in a natural apomictic $P$. simplex genotype after general artificial genome demethylation.

In H. pilosella, (51) hypothesized that sexual cues enabling meiotic tetrad formation in ovules, needed for aposporous initial cell formation are hormonal or epigenetic. Recently, in Paspalum rufum, (67) showed that several genes, previously associated with reproductive development, reproduction and apomixis, are affected by developmental stage-specific epigenetics marks.

In E. curvula Carballo et al. 2021 (68) showed that apomictic genotypes had higher DNA methylation levels than the sexual ones reinforcing the hypothesis that the genes controlling the sexual pathways are present but repressed in apomictic plants.

Owing to advances in modern molecular biology, such as various types of sequencing, including DNA sequencing in a single cell, detection of methylation, protein-protein interaction techniques, cell sorting, and other methods many aspects of DNA methylation, histone modification in chromatin alteration, and the role of small RNAs in regulation of plant development and interaction with the environment were studied. Of particular interest is the study of these processes in PMC and MMC during meiosis, gamete maturation, as well as during fertilization, embryogenesis, and further plant development. However, scientists have yet to unravel many aspects of epigenetics - what is the mechanism of "decision making" in methylation and modification of histones in a particular cell of a multicellular organism, how is epigenetic homeostasis maintained, and why does it change during certain developmental processes, what is the impetus for changes? An important issue is the transgenerational transmission of DNA and histone methylation and their populational role. The mechanism and the original cause of the asymmetry of epigenetic changes in the parent of origin modifications, that is, imprinting, also remains largely a mystery. Finally, the study of the adaptive value of epigenetic 
variability in reproductive and apomictic plants requires further research. Of course, intriguing discoveries and answers to many of the questions posed are waiting for us in the near future.

Acknowledgement

The study was supported by the Russian Foundation for Basic Research (RFBR) research grant No. 20-54-46002 CT_a to V.B.

\section{References}

1. Verhoeven KJF, Preite V. EPIGENETIC VARIATION IN ASEXUALLY REPRODUCING ORGANISMS. Evolution [Internet]. 2014 Mar 1 [cited 2021 Sep 27];68(3):644-55. Available from: https://onlinelibrary.wiley.com/doi/full/10.1111/evo.12320

2. Pikaard CS, Scheid OM. Epigenetic Regulation in Plants. Cold Spring Harbor Perspectives in Biology [Internet]. 2014 Dec 1 [cited 2021 Sep 27];6(12):a019315. Available from: http://cshperspectives.cshlp.org/content/6/12/a019315.full

3. Gehring M. Epigenetic dynamics during flowering plant reproduction: evidence for reprogramming? New Phytologist [Internet]. 2019 Oct 1 [cited 2021 Sep 27];224(1):91-6. Available from: https://onlinelibrary.wiley.com/doi/full/10.1111/nph.15856

4. Ono A, Kinoshita T. Epigenetics and plant reproduction: Multiple steps for responsibly handling succession. Current Opinion in Plant Biology. 2021 Jun 1;61:102032.

5. Law JA, Jacobsen SE. Establishing, maintaining and modifying DNA methylation patterns in plants and animals. Nature Reviews Genetics 2010 11:3 [Internet]. 2010 Feb 9 [cited 2021 Sep 27];11(3):204-20. Available from: https://www.nature.com/articles/nrg2719

6. Matzke MA, Mosher RA. RNA-directed DNA methylation: an epigenetic pathway of increasing complexity. Nature Reviews Genetics 2014 15:6 [Internet]. 2014 May 8 [cited 2021 Sep 27];15(6):394-408. Available from: https://www.nature.com/articles/nrg3683

7. Zhou M, Law JA. RNA Pol IV and V in gene silencing: Rebel polymerases evolving away from Pol II's rules. Current Opinion in Plant Biology. 2015 Oct 1;27:154-64.

8. Li Y, Kumar S, Qian W. Active DNA demethylation: mechanism and role in plant development. Plant Cell Reports [Internet]. 2018 Jan 1 [cited 2021 Sep 27];37(1):77. Available from: /pmc/articles/PMC5758694/

9. Tekel SJ, Haynes KA. Survey and summary: Molecular structures guide the engineering of chromatin. Nucleic Acids Research. 2017 Jul 1;45(13):7555-70.

10. Waddington $\mathrm{CH}$. The strategy of the genes. A discussion of some aspects of theoretical biology. With an appendix by $\mathrm{H}$. Kacser. The strategy of the genes $\mathrm{A}$ 
discussion of some aspects of theoretical biology With an appendix by $\mathrm{H}$ Kacser. 1957;

11. Waddington, C. H. 1942. Canalization of development and the inheritance of acquired characters. Nature 150 (3811):563-565.

12. Higo A, Saihara N, Miura F, Higashi Y, Yamada M, Tamaki S, et al. DNA methylation is reconfigured at the onset of reproduction in rice shoot apical meristem. Nature Communications 2020 11:1 [Internet]. 2020 Aug 14 [cited 2021 Sep 27];11(1):1-12. Available from: https://www.nature.com/articles/s41467020-17963-2

13. Brukhin V, Curtis MD, Grossniklaus U. The angiosperm female gametophyte: No longer the forgotten generation. SPECIAL SECTION: EMBRYOLOGY OF FLOWERING PLANTS CURRENT SCIENCE. 2005;89(11).

14. Cubas $P$, Vincent $C$, Coen $E$. An epigenetic mutation responsible for natural variation in floral symmetry. Nature 1999 401:6749 [Internet]. 1999 Sep 9 [cited 2021 Sep 27];401(6749):157-61. Available from: https://www.nature.com/articles/43657

15. Luo D, Carpenter R, Copsey L, Vincent C, Clark J, Coen E. Control of Organ Asymmetry in Flowers of Antirrhinum. Cell. 1999;99:367-76.

16. Manning K, Tör M, Poole M, Hong Y, Thompson AJ, King GJ, et al. A naturally occurring epigenetic mutation in a gene encoding an SBP-box transcription factor inhibits tomato fruit ripening. Nature Genetics 2006 38:8 [Internet]. 2006 Jul 9 [cited 2021 Sep 27];38(8):948-52. Available from: https://www.nature.com/articles/ng1841

17. Brukhin V. Molecular and genetic regulation of apomixis. Russian Journal of Genetics 2017 53:9 [Internet]. 2017 Sep 22 [cited 2021 Sep 27];53(9):943-64. Available from: https://link.springer.com/article/10.1134/S1022795417090046

18. Honys D, Reňák D, Twell D. Abbreviations: PMI, pollen mitosis I; PMII, pollen mitosis II 9 Male Gametophyte Development and Function.

19. Walker J, Gao H, Zhang J, Aldridge B, Vickers M, Higgins JD, et al. Sexual lineage specific DNA methylation regulates Arabidopsis meiosis. bioRxiv [Internet]. 2017 Oct 11 [cited 2021 Sep 27];201798. Available from: https://www.biorxiv.org/content/10.1101/201798v1

20. Borg M, Jacob Y, Susaki D, LeBlanc C, Buendía D, Axelsson E, et al. Targeted reprogramming of $\mathrm{H} 3 \mathrm{~K} 27 \mathrm{me} 3$ resets epigenetic memory in plant paternal chromatin. Nature Cell Biology 2020 22:6 [Internet]. 2020 May 11 [cited 2021 Sep 28];22(6):621-9. Available from: https://www.nature.com/articles/s41556-0200515-y

21. Slotkin RK, Vaughn M, Borges F, Tanurdžić M, Becker JD, Feijó JA, et al. Epigenetic Reprogramming and Small RNA Silencing of Transposable Elements in Pollen. Cell [Internet]. 2009 Feb 6 [cited 2021 Sep 27];136(3):461-72. Available from: http://www.cell.com/article/S0092867408016449/fulltext 
22. Calarco JP, Borges F, Donoghue MTA, van Ex F, Jullien PE, Lopes $T$, et al. Reprogramming of DNA methylation in pollen guides epigenetic inheritance via small RNA. Cell. 2012 Sep 28;151(1):194-205.

23. Lermontova I, Sandmann $M$, Mascher $M$, Schmit A-C, Chabouté M-E. Centromeric chromatin and its dynamics in plants. The Plant Journal [Internet]. 2015 Jul 1 [cited 2021 Sep 27];83(1):4-17. Available from: https://onlinelibrary.wiley.com/doi/full/10.1111/tpj.12875

24. Ingouff M, Selles B, Michaud C, Vu TM, Berger F, Schorn AJ, et al. Live-cell analysis of DNA methylation during sexual reproduction in Arabidopsis reveals context and sex-specific dynamics controlled by noncanonical RdDM. Genes \& Development [Internet]. 2017 Jan 1 [cited 2021 Sep 27];31(1):72. Available from: /pmc/articles/PMC5287115/

25. Baulcombe DC, Dean C. Epigenetic Regulation in Plant Responses to the Environment. Cold Spring Harbor Perspectives in Biology [Internet]. 2014 [cited 2021 Sep 27];6(9). Available from: /pmc/articles/PMC4142964/

26. Olmedo-Monfil V, Durán-Figueroa N, Arteaga-Vázquez $M$, Demesa-Arévalo $E$, Autran D, Grimanelli D, et al. Control of female gamete formation by a small RNA pathway in Arabidopsis. Nature [Internet]. 2010 Mar 25 [cited 2021 Sep 27];464(7288):628-32. Available from: https://ipn.elsevierpure.com/en/publications/control-of-female-gameteformation-by-a-small-rna-pathway-in-arab

27. Park K, Kim MY, Vickers M, Park J-S, Hyun Y, Okamoto T, et al. DNA demethylation is initiated in the central cells of Arabidopsis and rice. Proceedings of the National Academy of Sciences [Internet]. 2016 Dec 27 [cited 2021 Sep 27];113(52):15138-43. Available from: https://www.pnas.org/content/113/52/15138

28. Hsieh T-F, Ibarra CA, Silva P, Zemach A, Eshed-Williams L, Fischer RL, et al. Genome-Wide Demethylation of Arabidopsis Endosperm. Science (New York, NY) [Internet]. 2009 Jun 12 [cited 2021 Sep 27];324(5933):1451. Available from: /pmc/articles/PMC4044190/

29. Ibarra CA, Feng X, Schoft VK, Hsieh TF, Uzawa R, Rodrigues JA, et al. Active DNA demethylation in plant companion cells reinforces transposon methylation in gametes. Science. 2012 Sep 14;337(6100):1360-4.

30. Lu J, Zhang C, Baulcombe DC, Chen ZJ. Maternal siRNAs as regulators of parental genome imbalance and gene expression in endosperm of Arabidopsis seeds. Proceedings of the National Academy of Sciences [Internet]. 2012 Apr 3 [cited 2021 Sep 27];109(14):5529-34. Available from: https://www.pnas.org/content/109/14/5529

31. Grossniklaus U, Vielle-Calzada JP, Hoeppner MA, Gagliano WB. Maternal control of embryogenesis by MEDEA, a Polycomb group gene in Arabidopsis. Science. 1998 Apr 17;280(5362):446-50.

32. Creasey KM, Zhai J, Borges F, van Ex F, Regulski M, Meyers BC, et al. miRNAs trigger widespread epigenetically activated siRNAs from transposons in 
Arabidopsis. Nature 2014; 508(7496):411-5. Available from: https://www.nature.com/articles/nature13069

33. Bouyer D, Kramdi A, Kassam M, Heese $M$, Schnittger A, Roudier F, et al. DNA methylation dynamics during early plant life. Genome Biology 2017 18:1 [Internet]. 2017 Sep 25 [cited 2021 Sep 27];18(1):1-12. Available from: https://genomebiology.biomedcentral.com/articles/10.1186/s13059-017-13130

34. Kawakatsu T, Nery JR, Castanon R, Ecker JR. Dynamic DNA methylation reconfiguration during seed development and germination. Genome Biology. 2017 Sep 15;18(1).

35. Papareddy RK, Páldi K, Paulraj S, Kao P, Lutzmayer S, Nodine MD. Chromatin regulates expression of small RNAs to help maintain transposon methylome homeostasis in Arabidopsis. Genome Biology 2020 21:1 [Internet]. 2020 Sep 17 [cited $2021 \quad$ Sep 27];21(1):1-24. Available from: https://genomebiology.biomedcentral.com/articles/10.1186/s13059-02002163-4

36. Ingouff $M$, Rademacher $S$, Holec S, Šoljić L, Xin N, Readshaw A, et al. Zygotic resetting of the HISTONE 3 variant repertoire participates in epigenetic reprogramming in arabidopsis. Current Biology. 2010 Dec 7;20(23):2137-43.

37. Martínez G, Slotkin RK. Developmental relaxation of transposable element silencing in plants: functional or byproduct? Current Opinion in Plant Biology. 2012 Nov 1;15(5):496-502.

38. Grossniklaus U, Paro R. Transcriptional Silencing by Polycomb-Group Proteins. Cold Spring Harbor Perspectives in Biology [Internet]. 2014 Nov 1 [cited 2021 Sep 27];6(11):1-26. Available from: /pmc/articles/PMC4413232/

39. Ohad N, Yadegari R, Margossian L, Hannon M, Michaeli D, Harada JJ, et al. Mutations in FIE, a WD Polycomb Group Gene, Allow Endosperm Development without Fertilization. The Plant Cell [Internet]. 1999 Mar 1 [cited 2021 Sep 27];11(3):407-15. Available from: https://academic.oup.com/plcell/article/11/3/407/6008529

40. Köhler C, Hennig L, Bouveret R, Gheyselinck J, Grossniklaus U, Gruissem W. Arabidopsis MSI 1 is a component of the MEA/FIE Polycomb group complex and required for seed development. The EMBO Journal [Internet]. 2003 Sep 15 [cited 2021 Sep 27];22(18):4804. Available from: /pmc/articles/PMC212713/

41. Guitton A-E, Page DR, Chambrier P, Lionnet C, Faure J-E, Grossniklaus U, et al. Identification of new members of Fertilisation Independent Seed Polycomb Group pathway involved in the control of seed development in Arabidopsis thaliana. Development [Internet]. 2004 Jun 15 [cited 2021 Sep 27];131(12):297181. Available from: www.plantsci.cam.ac.uk/Haseloff/home.html

42. Vielle-Calzada J-P, Thomas J, Spillane C, Coluccio A, Hoeppner MA, Grossniklaus $U$. Maintenance of genomic imprinting at the Arabidopsis medea locus requires zygotic DDM1 activity. Genes \& Development [Internet]. 1999 [cited 2021 Sep 27];13(22):2971. Available from: /pmc/articles/PMC317158/ 
43. Gehring $M$, Huh JH, Hsieh T-F, Penterman J, Choi Y, Harada JJ, et al. DEMETER DNA Glycosylase Establishes MEDEA Polycomb Gene Self-Imprinting by AlleleSpecific Demethylation. Cell [Internet]. 2006 Feb 10 [cited 2021 Sep 27];124(3):495. Available from: /pmc/articles/PMC4106368/

44. Tiwari VK, McGarvey KM, Licchesi JDF, Ohm JE, Herman JG, Schübeler D, et al. PcG Proteins, DNA Methylation, and Gene Repression by Chromatin Looping. PLOS Biology [Internet]. 2008 [cited 2021 Sep 27];6(12):e306. Available from: https://journals.plos.org/plosbiology/article?id=10.1371/journal.pbio.0060306

45. Becker C, Hagmann J, Müller J, Koenig D, Stegle O, Borgwardt K, et al. Spontaneous epigenetic variation in the Arabidopsis thaliana methylome. Nature 2011 480:7376 [Internet]. 2011 Sep 20 [cited 2021 Sep 27];480(7376):245-9. Available from: https://www.nature.com/articles/nature10555

46. Schmitz RJ, Schultz MD, Lewsey MG, O'Malley RC, Urich MA, Libiger O, et al. Transgenerational epigenetic instability is a source of novel methylation variants. Science. 2011 Oct 21;334(6054):369-73.

47. Paszkowski J, Grossniklaus U. Selected aspects of transgenerational epigenetic inheritance and resetting in plants. Current Opinion in Plant Biology. $2011 \mathrm{Apr}$ 1;14(2):195-203.

48. Tricker PJ, López CMR, Gibbings G, Hadley P, Wilkinson MJ. Transgenerational, dynamic methylation of stomata genes in response to low relative humidity. International Journal of Molecular Sciences [Internet]. 2013 Apr [cited 2021 Sep 27];14(4):6674-89. Available from: https://www.meta.org/papers/transgenerational-dynamic-methylation-ofstomata/23531533

49. Albertini E, Barcaccia G, Carman JG, Pupilli F. Did apomixis evolve from sex or was it the other way around? Journal of experimental botany. 2019 Jun 1;70(11):2951-64.

50. Garcia-Aguilar M, Michaud C, Leblanc O, Grimanelli D. Inactivation of a DNA methylation pathway in maize reproductive organs results in apomixis-like phenotypes. The Plant cell [Internet]. 2010 [cited 2021 Sep 27];22(10):3249-67. Available from: https://hal.archives-ouvertes.fr/hal-00730367

51. Drews GN, Koltunow AMG. The Female Gametophyte. https://doi.org/101199/tab0155 [Internet]. 2011 Dec 1 [cited 2021 Sep 27];2011(9):e0155. Available from: https://bioone.org/journals/the-arabidopsisbook/volume-2011/issue-9/tab.0155/The-Female-

Gametophyte/10.1199/tab.0155.full

52. Koltunow AMG, Johnson SD, Rodrigues JCM, Okada T, Hu Y, Tsuchiya T, et al. Sexual reproduction is the default mode in apomictic Hieracium subgenus Pilosella, in which two dominant loci function to enable apomixis. The Plant Journal [Internet]. 2011 Jun 1 [cited 2021 Sep 27];66(5):890-902. Available from: https://onlinelibrary.wiley.com/doi/full/10.1111/j.1365-313X.2011.04556.x 
53. Huanca-Mamani W, Garcia-Aguilar M, León-Martínez G, Grossniklaus U, VielleCalzada J-P. CHR11, a chromatin-remodeling factor essential for nuclear proliferation during female gametogenesis in Arabidopsis thaliana. Proceedings of the National Academy of Sciences [Internet]. 2005 Nov 22 [cited 2021 Sep 27];102(47):17231-6. Available from: https://www.pnas.org/content/102/47/17231

54. Xiao W, Custard KD, Brown RC, Lemmon BE, Harada JJ, Goldberg RB, et al. DNA Methylation Is Critical for Arabidopsis Embryogenesis and Seed Viability. The Plant Cell [Internet]. 2006 [cited 2021 Sep 27];18(4):805. Available from: /pmc/articles/PMC1425851/

55. Baroux C, Pien S, Grossniklaus U. Chromatin modification and remodeling during early seed development. Current Opinion in Genetics and Development. 2007 Dec;17(6):473-9.

56. Curtis MD, Grossniklaus U. Molecular control of autonomous embryo and endosperm development. Sexual Plant Reproduction 2007 21:1 [Internet]. 2007 Dec 19 [cited 2021 Sep 27];21(1):79-88. Available from: https://link.springer.com/article/10.1007/s00497-007-0061-9

57. Singh M, Goel S, Meeley RB, Dantec C, Parrinello H, Michaud C, et al. Production of Viable Gametes without Meiosis in Maize Deficient for an ARGONAUTE Protein. The Plant Cell [Internet]. 2011 Feb 1 [cited 2021 Sep 27];23(2):443-58. Available from: https://academic.oup.com/plcell/article/23/2/443/6094958

58. Carman JG, Jamison M, Elliott E, Dwivedi KK, Naumova TN. Apospory appears to accelerate onset of meiosis and sexual embryo sac formation in sorghum ovules. BMC Plant Biology 2011 11:1 [Internet]. 2011 Jan 11 [cited 2021 Sep 27];11(1):113. Available from: https://bmcplantbiol.biomedcentral.com/articles/10.1186/1471-2229-11-9

59. Hörandl $E$, Hadacek $F$. The oxidative damage initiation hypothesis for meiosis. Plant Reproduction 2013 26:4 [Internet]. 2013 Aug 31 [cited 2021 Sep 27];26(4):351-67. Available from: https://link.springer.com/article/10.1007/s00497-013-0234-7

60. Gao L. Pharmacologically Induced Meiosis Apomeiosis Interconversions in Boechera, Arabidopsis and Vigna. All Graduate Theses and Dissertations [Internet]. 2018 Aug 1 [cited 2021 Sep 27]; Available from: https://digitalcommons.usu.edu/etd/7222

61. Shea N, Pen I, Uller T. Three epigenetic information channels and their different roles in evolution. Journal of Evolutionary Biology [Internet]. 2011 Jun [cited 2021 Sep 27];24(6):1178. Available from: /pmc/articles/PMC3116147/

62. Lynch M. Destabilizing Hybridization, General-Purpose Genotypes and Geographic Parthenogenesis. https://doi.org/101086/413902 [Internet]. 2015 Oct 22 [cited 2021 Sep 27];59(3):257-90. Available from: https://www.journals.uchicago.edu/doi/abs/10.1086/413902

63. Calderini O, Chang SB, de Jong H, Busti A, Paolocci F, Arcioni S, et al. Molecular cytogenetics and DNA sequence analysis of an apomixis-linked BAC in 
Paspalum simplex reveal a non pericentromere location and partial microcolinearity with rice. Theoretical and Applied Genetics 2006 112:6 [Internet]. 2006 Feb 7 [cited 2021 Sep 27];112(6):1179-91. Available from: https://link.springer.com/article/10.1007/s00122-006-0220-7

64. Conner JA, Goel S, Gunawan G, Cordonnier-Pratt MM, Johnson VE, Liang C, et al. Sequence analysis of bacterial artificial chromosome clones from the apospory-specific genomic region of Pennisetum and Cenchrus. Plant Physiology. 2008 Jul;147(3):1396-411.

65. Zappacosta DC, Ochogavía AC, Rodrigo JM, Romero JR, Meier MS, Garbus I, et al. Increased apomixis expression concurrent with genetic and epigenetic variation in a newly synthesized Eragrostis curvula polyploid. Scientific Reports 2014 4:1 [Internet]. 2014 Apr 8 [cited 2021 Sep 27];4(1):1-7. Available from: https://www.nature.com/articles/srep04423

66. Podio M, Cáceres ME, Samoluk SS, Seijo JG, Pessino SC, Ortiz JPA, et al. A methylation status analysis of the apomixis-specific region in Paspalum spp. suggests an epigenetic control of parthenogenesis. Journal of Experimental Botany. 2014 Dec 1;65(22):6411-24.

67. Soliman M, Podio M, Marconi G, Marsico M di, Ortiz JPA, Albertini E, et al. Differential Epigenetic Marks Are Associated with Apospory Expressivity in Diploid Hybrids of Paspalum rufum. Plants 2021, Vol 10, Page 793 [Internet]. 2021 Apr 17 [cited 2021 Sep 27];10(4):793. Available from: https://www.mdpi.com/2223-7747/10/4/793/htm

68. Carballo J, Zappacosta D, Marconi G, Gallardo J, Marsico M di, Gallo CA, et al. Differential Methylation Patterns in Apomictic vs. Sexual Genotypes of the Diplosporous Grass Eragrostis curvula. Plants 2021, Vol10(5):946. Available from: https://www.mdpi.com/2223-7747/10/5/946/htm 